\title{
Feedback amidst New Assessment Culture in Malawian Primary Schools
}

\author{
Wezzie K. M. C. Chiziwa1, Esthery D. Kunkwenzu² \\ ${ }^{1}$ Department of Education and Teaching Studies, University of Livingstonia, Mzuzu, Malawi \\ ${ }^{2}$ Department of Curriculum and Teaching Studies, University of Malawi, Zomba, Malawi \\ Email:wchiziwa@unilia.ac.mw, ekunkwenzu@cc.ac.mw
}

How to cite this paper: Chiziwa, W. K. M. C., \& Kunkwenzu, E. D. (2022). Feedback amidst New Assessment Culture in Malawian Primary Schools. Open Journal of Social Sciences, 10, 100-116.

https://doi.org/10.4236/jss.2022.101008

Received: November 24, 2021

Accepted: January 11, 2022

Published: January 14, 2022

Copyright $\odot 2022$ by author(s) and Scientific Research Publishing Inc. This work is licensed under the Creative Commons Attribution International License (CC BY 4.0).

http://creativecommons.org/licenses/by/4.0/

\begin{abstract}
The study investigated primary school teacher feedback practices amidst the new assessment culture. This was in an attempt to understand how teacher feedback meaningfully contributes to assessment for learning under the umbrella of continuous assessment. The study used a qualitative approach in order to understand feedback practices through classroom observation, face-to-face interview and document analysis. The findings of the study revealed that teachers in the study dominantly used oral feedback and grades as a form of informal and formal feedback respectively. With regards to value of feedback, five out of eight participating teachers did not attach value of using feedback in order to inform learning. These teachers merely considered learners performance as a tool to meet the administrative requirement of promoting them to another class which is a summative dimension. The assessment results were neither used to change the teaching approaches nor assist learners in their learning gaps. Three participants attempted to use assessment results to improve the learner's performance by engaging them in remedial lessons in order to fill their learning gaps. While some teachers attempted to use assessment results to inform learning, high-class sizes and workload hampered their efforts. The study reveals that the operating context for effective implementation of CA feedback practices is still hostile in the participating schools which needs to be addressed.
\end{abstract}

\section{Keywords}

Continuous Assessment, Formative Assessment, Feedback, Feed Forward

\section{Introduction}

In an effort to improve service delivery in the Malawi education system, the 
Ministry of education embraced outcome-based education in its 2001 Primary Curriculum and Assessment Reform (PCAR) (MOE \& MIE, 2007). The conceptualization of the primary school curriculum and assessment reform was necessitated by the deterioration of the quality of education in Malawi. The 1991 curriculum was characterized by high school dropout rates and repetition rates (MoEST \& MIE, 2006). The reform was a direct response to Malawi's vision 2020 which envisaged that the provision of quality education is instrumental in spearheading national development.

The policy documents acknowledge that the education sector is marred with myriad challenges such as poor and inadequate education infrastructure, shortage of qualified teachers, inefficiencies in the education system, high absenteeism, and repetition and dropout rates. One of the goals that Ministry of Education in Malawi intends to achieve is to build a highly-skilled population that will contribute to socio-economic development of the country. Reviewing the curriculum was one of the strategies put in place in order to address the development challenges.

The consultation process for the curriculum reform involved various stakeholders, at the national level, teachers, headteachers, pupils, men, women, non-school going children and various other stakeholders. In addition, 60 inspection visits to various schools were made to inform the process. Apart from the local experiences, literature review from the Southern Africa Development Community (SADC) region was conducted. Experiences from a total number of six countries, namely, Uganda, Tanzania, Zambia, Zimbabwe, Namibia and South Africa were taken into consideration (MoEST \& MIE 2006).

The stakeholder consultation, the literature, and document review revealed major challenges in the primary education system. It was noted that there was poor return on investment in terms of learning outcomes; literacy and numeracy rates were very low characterised by $0.6 \%$ of learners who could read to desirable levels by standard 6 (Kaambankadzanja, 2005a). Other challenges compiled by Kaambankadzanja (2005a) included; Inadequate teacher support on the 1991 curriculum, ad hoc accommodation of emerging issues in the curriculum such as HIV/AIDS, democracy and human rights, rapid population growth and environmental degradation resulting into an overloaded curriculum. In addition, the introduction of free primary education (FPE) resulted into constrained school resources as the number of learners almost doubled. These challenges led to the drop in quality of education characterised by high school dropout, absenteeism and high repetition rates.

Various countries provided insights into the challenges faced by the Malawi primary education system. Aspects which were recommended included; adoption of the breakthrough to literacy from Zambia; Provision of basic pre-school facilities at every school from Tanzania; introduction of hardship allowances from those who teach in rural areas; and reduction of learning areas from South Africa and Namibia respectively (Kaambankadzanja, 2005b). 
Having considered input from various stakeholders and experiences from other countries, Malawi considered the adoption of Outcome-Based Education $(\mathrm{OBE})$ as a main reform. OBE in Malawi was dominantly modelled on the curriculum South Africa education system adopted in early 1997 under the banner Curriculum 2005. Curriculum 2005 stressed the paradigm shift from rigid content-based to outcome-based with emphasis on learner-centered teaching and continuous assessment (Jansen, 1998).

\subsection{Study Rationale}

Feedback, following any form of assessment, is instrumental in supporting learning. The rationale of the study was therefore to understand teacher feedback practices amidst new assessment culture. In this way, the study brings awareness to both practitioners and Ministry of Education officials on the nature of feedback practices in the process of implementing the curriculum. In light of the study findings, the study suggests ways of improving feedback practices that support learning.

\subsection{Problem Statement}

$\mathrm{CA}$ as an integral part of teaching and learning process is meant to provide information to both the teacher and the learner on their teaching and learning process respectively. Assessment results provide vital feedback to both the teacher and the learner. It is undeniable fact that both teacher and learner feedback is the axis of the process. Despite the fact that feedback plays an important role in the academic life of learners, it is often ignored (Boud, 2000). In their studies on formative assessment, Black and Wiliam (1998) underscored that substantial benefits associated with formative assessment accrued from feedback. While this is the case, the primary education institutions and teachers in Malawi still operate in the strained environment characterised by, high pupil permanent classroom ratio (PqCR), high pupil-qualified teacher ratio, high repetition rates, and low completion rates (MoEST, 2019). This data portrays a gloomy situation on the ground. It remains unclear whether teachers manage to provide meaningful feedback to learners at the same time use learner feedback to adjust their teaching.

\subsection{Research Questions}

The following was the main research question that guided the study:

1) What are the teacher feedback practices during assessment activities?

The following specific research questions guided the study.

1) What forms of feedback do teachers use during the teaching and learning process?

2) How do teachers use feedback in order to facilitate learning?

3) How does learner feedback influence teacher instruction?

4) What are the challenges that teachers face in providing feedback? 


\section{Literature Review}

\subsection{Continuous Assessment and Associated Benefits}

Continuous assessment can be defined as all ongoing activities undertaken by teachers and learners in judging themselves, which provide information to be used as feedback in order to modify teaching and learning activities in which they are engaged (Macintosh, 2003). This information is collected over time most of the times by teachers in order to assess what learners know, understand and can do (Chilora, du Plessis, Kamingira, Mchazime, Miske, Phillips, \& Zembeni, 2003).

Initially, assessment results were dominantly used for certification purposes (Bill \& Marie, 2014). Such assessment practices served the summative purpose. Traditionally the dominant assessment task was recall-based which promoted rote learning (DoE, 2008). Falchikov (2005) highlighted that among others, summative assessment does not provide deep learning and that emphasis on examinations contributes to students stress with little or no feedback.

The criticism on summative assessment led to the popularisation of formative assessment which is sometime known as assessment for learning under the brand of continuous assessment (CA). It is argued here that CA promotes learning since it is designed to assist the learning process. Black and Wiliam (1998), affirm that there is resounding research-based evidence that CA raises standards even to learners who are considered as low achievers. Review of literature by various scholars; support the claim that formative assessment practices such as the use of peer assessment, self-assessment, formative use of summative assessment can double the learner's performance (Black \& Wiliam, 1998; Crooks, 1998; Natriello, 1987). The benefits of continuous assessment stem from the nature and effective use of feedback.

\subsection{Continuous Assessment and Feedback}

Feedback is believed to play a central role in the teaching and learning process. This can be used by both the teacher and the learner. Shute (2008: p. 154) defines feedback as "information communicated to the learner that is intended to modify his or her thinking or behavior for the purpose of improving learning." In a similar manner, Hattie and Timperley (2007: p. 81) define feedback as "information provided by an agent (i.e. teacher, peer, parent and self-experience) regarding aspects of one's performance or understanding." Ramaprasad (1983) notes that for a teacher, feedback assists in the decision making regarding learner readiness, diagnostic and remediation, students use it to monitor their strengths and weaknesses.

In Ramaprasad's contention, feedback that does not close the learning gap is unproductive (Ramaprasad, 1983). Brown (2004) contends that the main purpose of continuous assessment is to improve learning through the provision of quality feedback. Brookhart (2008) points out that feedback is crucial in that it enables the receiver to know what they need to improve or aspects that they have 
done well, and what to do next. This is particularly useful if feedback is followed with information on what they are supposed to do next.

Apart from the receiver, teachers as assessors benefit from the outcomes of assessment in that feedback helps them adjust their teaching to address the learning gaps. Feedback is therefore an important component that follows any form of assessment. There are various forms of feedback used during classroom assessment activities.

\subsection{Forms of Feedback}

Feedback takes various forms, of particular interest, is oral and written feedback. Oral feedback is usually done during day-to-day lesson activity or at the opportune time when the teacher meets the learner for discussions. Oral feedback is a powerful tool that drives the learning process. Written feedback is generally provided on the learners' scripts usually for summative tasks. In order for written feedback to be effective, Ferris (2014), points out that it must be followed by oral feedback where a teacher is involved in a face-to-face talk with the learner to clarify learning gaps and allow students to ask questions.

In a study by Volante and Beckett (2017), it was noted that teachers adopted the provision of written feedback without grades. However, they were faced with pressure from parents who were more interested in the provision of more evaluative reports. Other scholars have argued that if assessment focus is on grades instead of informing learning, then it loses the essence of formative in favour of summative assessment (Gorlewski, 2008).

Rust (2002) compiled literature on how teachers would use feedback to support learning. Rust (2002) contended that effective use of feedback must be prompt, must start off with positive reinforcement, must include a summary of your view of the assignment, must balance motive and negative comments, explain your comments, suggest specific problems, make opportunity to discuss the assignment, and make general suggestions on how to improve in their subsequent work.

Similarly, Nicol and MacFarlane-Dick (2006), point out that effective feedback must clarify what good performance is, and help students understand where they are going. In addition, feedback must promote student motivation and self-esteem.

Rust (2002) stresses that the provision of feedback alone is not enough, but teachers need to constantly engage the learner actively as well. While these aspects are comprehensive, some studies revealed that teachers do not provide feedback let alone use the results of assessment to support learning (Berhe \& Embiza, 2015).

The literature review has shown that continuous assessment alone is not responsible for quality learning. The nature and quality of feedback are very instrumental in attaining quality learning. There are various forms of feedback, each playing a crucial role towards effective teaching and learning. 


\section{Research Methodology}

\subsection{Research Design}

The study used a qualitative methodology using a case study approach. The case study methodology was appropriate for this research because it helped in providing a deeper understanding of the classroom dynamics in as far as feedback is concerned. Kothari (2004: p. 113) highlights that a case study focuses on a comprehensive study of "a person on what he does, what he thinks he does and has done and what he expects to do and says he ought to do". Similarly, this study focused on teacher feedback practices while implementing CA. It is for this reason that the case study approach was appropriate in an effort to understand teacher feedback practices.

\subsection{Study Site}

Three primary schools from Rumphi district were selected in this study. For the purpose of anonymity and confidentiality each school was given a pseudonym. Alphabetical letters B, L, and S were used in place of the real names. In this study, eight primary school teachers were sampled. Each school and participating teachers were given pseudonym in order to ensure anonymity. Names of the schools were referred to as school B, L and S. Each teacher per school was labelled T1, T2 and T3. When describing the participating teachers, the first letter represented the name of the school followed by the labelling for a specific teacher. Based on that, the sample had the following participating teachers, BT1, BT2, BT3, LT1, LT2, ST1, ST2, and ST3, making a total of eight teachers.

\subsection{Sampling}

The study used purposive sampling in selecting participants with the aim of choosing participants who best suit the criteria for the study (Merriam, 2002). The purpose was to select teachers who had been using continuous assessment for a number of years. Eight primary school teachers were selected in order to get an in-depth understanding in the feedback practices amidst new assessment culture.

\subsection{Data Collection}

In this study, data was generated through used face-to-face interview with teachers. An interview is a purposeful data generation procedure in form of dialogue in which the researcher tries to obtain information from participating teachers (Gay, Mills, \& Airasian, 2006). This study used both unstructured and semi structured interviews in a face to face approach. The structured and semi structured approach provided me with the flexibility in data generation (Walliman, 2011). Interviews were very important in that they provided a doorway in exploring teacher understanding on feedback mechanism used during all the assessment activities

Another data collection tool used in this study was lesson observation. Walli- 
man (2011) notes that observation just like other strategies help to record data about events and activities. What is observed is the event or phenomenon in action (Tuckman, 1994). This study was interested in the actions and activities teachers engage in the provision of feedback during the teaching and learning process. Lesson observation therefore offered an opportunity for data triangulation. A total of forty lesson observations were done. Each lesson observed took thirty minutes. Five lesson observations were done on each of the eight participants.

Finally, Yin (2002) recognizes a critical role of documents in any case study. He argues that documents help to corroborate with evidence from other sources. Teachers are required to come up with documentation such as, learner progress books, lesson plans, schemes and records of work and assessment tasks. In addition, students work may provide valuable information about classwork. These are important documents which highlight important episodes regarding the teaching and learning process. In this study, students work was checked to see the nature of feedback provided to learners on their written assessment tasks.

\subsection{Data Analysis}

MacMillan (2004) identifies three steps of analysing qualitative data and these are: organising of the data, summarising the data and then interpreting the data. With regard to familiarisation of data, I got familiar with it as I personally carried out the data generation through face to face interview, observation and document analysis and field notes. An increased level of familiarisation of interview data involved thorough listening and re-listening of the recorded interview and articulate reading of transcribed data. The interview was transcribed and later on thematic analysis was done through coding.

\section{Results and Findings}

The study findings focused on three major aspects and these are; the forms of feedback provided to learners during teaching as well as on written assessment tasks, how teachers used assessment results and how learner's feedback inform the teaching and the challenges encountered when providing feedback.

\subsection{Forms of Feedback}

The study found out that teachers were engaged in constant feedback during the teaching and learning process. The following extracts provide a snapshot of classroom vignettes (Chiziwa \& Kunkwenzu, 2021).

Box 1 provides evidence of classroom feedback provided to learners during the teaching and learning process. The class is characterised by question and answer method of teaching. From the lesson extract teacher ST2 commonly reacts in two ways from learner's response. Firstly the teacher responds by either praising the learner or simply ignoring the learner for the correct and wrong response respectively.

In Box 2, the teacher just repeated the same answers given by learners as an 
overall summary of the lesson. In addition, the teacher provided feedback to learners by explaining what was considered as the correct answers on the assigned work.

Box 1. An extract of a lesson showing teacher feedback during teaching.

Teacher ST2

Teacher: as I have already said, today we are going to discuss on a topic of forest... so have you ever heard about the term forest?

All learners: yes (in unison)

Teacher: do you know a forest?

All learners: yes (in unison)

Teacher: who can define the term forest? Forest not forestry but forest, what is a forest? Learner 1: where trees and grasses are planted

Teacher: thank you, anyone else with a different definition? Boys what's happening... anyone

Learner 2: is a place that live animals

Teacher: is a place where animals live (hesitant) Okay thank you for your trial, anyone else

Learner 3: a place where nature lives

Teacher: okay thank you for your idea anyone else... okay a forest is a large land of trees, the trees can be planted or natural

Box 2. Lesson observation summary for teacher ST1.

Subject: Social and Environmental Sciences

Topic: Population

Class: Standard 6

Number of learners: 70

School: S

Teacher: ST1

Lesson summary

The teacher began the lesson by reminding learners that in the previous lesson they discussed about physical features. He asked them to define the term physical features. Two learners responded to the question. But when he asked them another question on examples of physical features most learners showed enthusiasm to respond.

He then told learners that they were going to learn about population. He asked the learners to be in groups and discuss the meaning of the term population and population density. During the presentation one group gave the meanings of the two terms. But the rest of the group members gave the same response. The impression was that some group members were just repeating what their friends presented. Finally the teacher consolidated by repeating the learner's responses. He then highlighted that figures of population were derived from census and gave explanation of the 2018 census in Malawi. Later on, he asked learners to discuss factors influencing high population density in the southern region. Learners came up with only two responses and these were; availability of industries and vast space. The teacher then came up with other factors. Finally, he concluded by asking learners the definitions of population and population density and factors resulting into high densities in the southern region.

Teacher ST1 lesson observation, 03.10.2018 time 11:15 am 
Document analysis for two different teachers was extracted to check what kind of feedback learners received on their written work. Two papers for each teacher were collected to check how teachers provided feedback to learners who score high and low grades. The following are the extracts

Two extracts in Figure 1 and Figure 2 show a similar pattern by teachers in the way they handle the marking and feedback. It is noted from the extracts that those who perform well, a remark of a motivation word "good" is written on their script. The scripts show ticks and crosses for correct and incorrect responses respectively. Both papers indicate an overall grade.

\subsection{Use of Learner Feedback}

Use of feedback is an important element in the CA system. Feedback to a larger extent is a definer of effective CA practices aiming at informing learning. The findings of the study revealed that CA results are a feedback from learners dominantly functions as a tool to promote learners to another class. The following had this to say

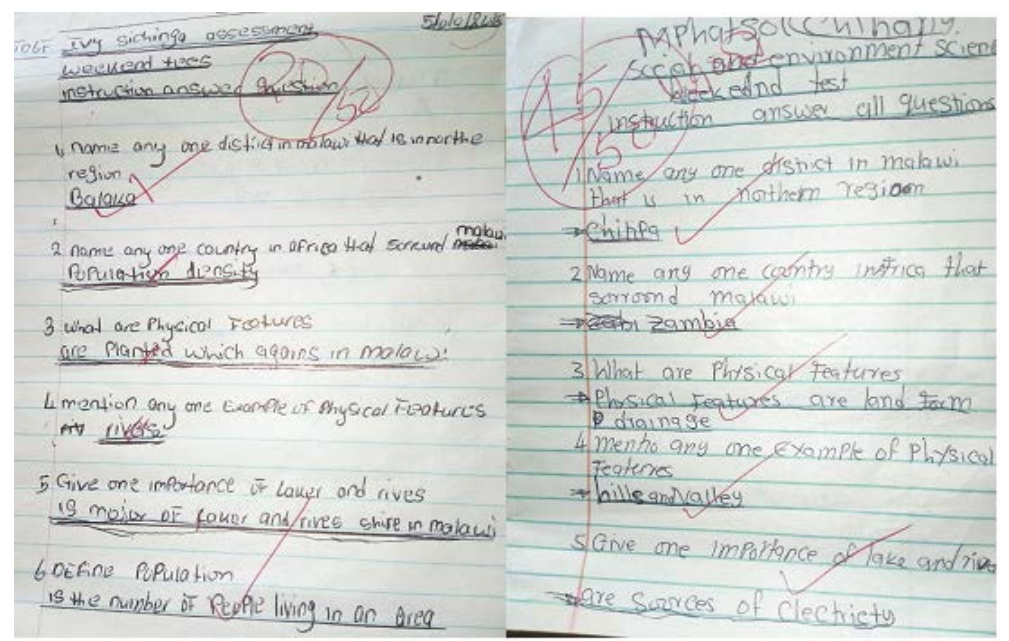

Figure 1. An extract of a marked script by Teacher LT1.
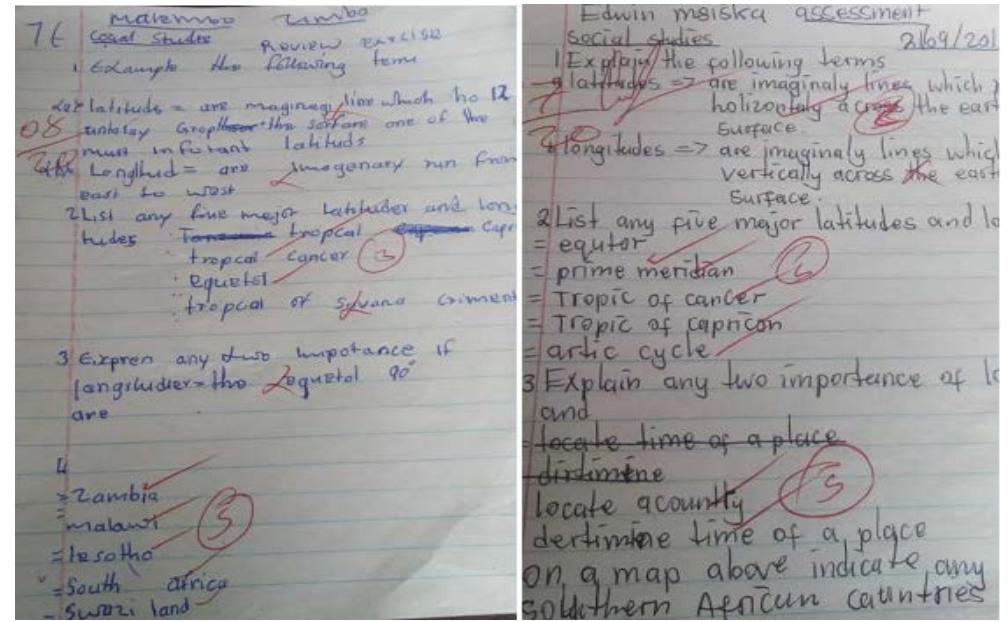

Figure 2. An extract of a marked script by Teacher ST2. 
The results from the CA available can provide us with information whether to promote the learner to another class. (BT2, Face to Face interview, 21.06.2018)

... that each and every month we are supposed to assess them yaah so it comes sometimes may you find that a learner at the end of the term he or she don't write exams because of sickness or some problems so we go back to the CA... So that assist us to make to promote that learner from one level to another so yah so is good (teacher ST1, face to face interview, 20.04.2018) ... so that they should perform well at the end and also it helps in terms of ahh when a learners is sick during final exams we just use the past performance of that learner of which also aah even. (Teacher ST2 face to face interview, 19.04.2018, 8 am)

But now you find out that by the end of the term you are going to promote learners from this class to this class. May be that term by the end of the term you will find that learners has not attended may be because he is sick or may have gone somewhere else, so through CA we just get the information because he was just writing monthly so that ia can say CA we are able to promote learners based on that CA. (Teacher LT1, face to face interview)

While five teachers stressed that assessment results are used to promote learners to another class, teacher BT3 and ST3 indicated that they used CA to improve their teaching and provide necessary support to learners. BT3 had this to say:

For example you have known that this and that one are under grade one, the learners that need support. For myself in my class I have 12 learners who after knocking off we knock off at quarter to two from quarter to two up to 20 past 3 I have another class for the learners that are not able to demonstrate learning outcomes. Others cannot even read in my class others cannot give a correct answer by using English language. They have mastered in Chitumbuka (one of the local language) so at first I help them so that they can understand English and secondly they can be able to read and write English, because most of the subjects are taught in English. So if the learner cannot be able to understand English cannot be able to understand the subject. (BT3 face to face interview, 04.10.2018, $10 \mathrm{am}$ )

\subsection{Challenges Associated with Provision of Feedback}

The study noted that the participating teachers were facing some challenges that deterred effective use of feedback. The major challenges highlighted by participating teachers were learner absenteeism and high workload.

\subsubsection{Learner Absenteeism}

Participating teachers reported that learner absenteeism posed a major problem in carrying out CA and the provision of assistance. The following were the responses from selected participants. 
But as a teacher on factors discouraging CA and feedback I can talk of absenteeism of learners. Today not coming, tomorrow he comes but to the staffing there is no problem. But I can talk of absenteeism and deserting of the tests by the learners. (Teacher LT2)

Learners absent themselves from tests, so I have difficulties in assigning a grade to such learners at the end. (Teacher BT2)

Since I have already said that the learners are not always happy when asking them questions... Will see some will move out from class some will not write. So for you to trace what grade are they because they have not written the test it's difficult... they like writing the end of term test only. (Teacher LT1)

Learner absenteeism is seen as hindering teachers in providing both assessment and provision of feedback to support learning.

\subsubsection{High Workload and Large Class Sizes}

The findings of the study revealed that high workload hampered teachers from effectively providing feedback to individual learners which is a prerequisite to effective formative assessment. It was noted that some teachers were assigned almost the whole class teaching five to six subjects in the same class. For instance, teacher BT3 at school B had almost all the subjects for one class allocated to her. A number of teachers said the following:

As I have said that here in primary schools you find someone teaching ten subjects... nine someone having the whole class and also taking some subjects somewhere like me here in standard seven I am taking... am taking... I have got my own class and there are over 70 learners so it's a tiresome work to a teacher so you know because of shortage of teachers. (Teacher ST1) its... the large class... large class... and also books had it been that they are enough books for each and every learner it could be better because some of them they just hear from the class that's all when they go back home whenever you say go and read they will not read because they don't have books yaahh. (Teacher ST2)

Staff eeh what I mean is that if you are having many subjects this one is difficult. May be a teacher you can have may be ten subjects, so ten subjects as an individual for you to do that aah it's difficult. (Teacher LT1)

During classroom observation, I noted two teachers connecting one lesson to the other. When I was conducting lesson observation for teacher BT1 who started teaching social and environmental sciences subject which was meant for my study, after the bell rung for the next lesson she started teaching English. Again the bell rang, she started teaching Chichewa until break time and yet after break time she was to continue with the learners in the other subject.

This similar experience happened when observing teacher LT1 and ST1. It is not a surprise that one of the participants indicated that they sometimes guess the grades for learners if they had not administered any CA. Teacher BT1 had 
this to say:

The challenge that is when we administer end of term test and assessment it is difficult to assess all the subjects. You will find that you just assess twice. In other areas we just guess that if this learner gets this grade in this other test (the test does not exist but a grade is created for the learner) he can score like this, so that becomes the challenge. (Teacher BT1)

Similar sentiments were echoed by Teacher BT3 when asked about her experiences with CA and feedback. In her response, there were some elements that CA assists them to create grades for learners who miss examination for one reason or another. She had this to say:

So if you have the continuous assessment, you can look back on how he or she was doing and you can be able to give a learner a level or a grade. Because without those assessment tools you can't trace the level or grade in which the learner is. But because of CA even if the learner cannot sit for exams you still get the grade or level for the learner. (Teacher BT3)

In summary, the findings of the study show that oral feedback was provided to learners in everyday classroom activities. Teachers merely praised learners for good work and sometimes ignored wrong answers without further comments. The formal assessment tasks were merely graded with a numerical grade with no comments save for motivation words such as "good" or "very good" for good work only. Learner's assessment results were used for promotion to another class or attainment of the grade. The findings show that effective feedback was hampered by large class sizes and learner absenteeism.

\section{Discussion}

The findings of the study indicate that feedback practices apply to both formal and informal situations. Informal situations constitute day to day class interactions with learners through questioning. Teacher feedback in this situation varied in three ways. From classroom observation reports presented in Box 1 and Box 2 participating teacher ST2 and ST1 simply provided feedback by praising the learners response or ignoring the learner altogether. In addition, the participating teachers simply repeated learner's responses as an emphasis that responses were correct or gave out explanation in areas they felt learners were unable to respond accordingly. By simply praising a learner without associated explanation is not powerful enough, as Ramaprasad (1983) puts it that feedback must provide an opportunity to improve the subsequent work.

Feedback practices for teacher ST1 was not encouraging to learners who attempted to respond to the task. The teacher's action showed an element of ignoring learner's response. In addition, by saying “thank you for your trial", teacher ST1 did not strategically guide the learner towards learning the concept. In other words, the statement "thank you for your trial' lacks scaffolding element to take the learner from within the zone of their familiarity to advanced 
work. Further, ignoring learners was demoralising and had the ability of denigrating learner self-esteem.

The teacher did not attempt to engage with the learners in a meaningful dialogue in order to clarify their responses but was merely focussing on getting the correct response. The actions of ST1 by giving the same answers that learners responded, does not make learners grow in analysing and explaining issues. The teacher did not further examine together with the learners on the responses that the group members made even though the responses did not make sense in the absence of further explanation, for instance "the reason for high population is availability of vast space". It is important for learners to know why their responses are particularly inadequate. Such an omission in clarifying the issue is in itself feedback that constructively confirms the learner's response as right which is not necessarily correct.

Just as teacher ST1, teacher ST2 did not meaningfully engage learners in the discussion and ended up giving learners already prepared responses thereby making them inactive. It should be noted that that the informal spontaneous feedback during the interactive lesson is very important. Although the spontaneous feedback is not graded, it has the ability to build the self-esteem of learners or destroy the same.

The formal assessment practices of weekly tests were characterised by the giving of grades as a form of feedback. Learner's scripts were simply marked correct or wrong. A similar pattern was noted from two different teachers who administered tests as a form of CA. Scripts marked by teacher LT1 and ST2 has a similar pattern of feedback. Learners were simply provided with a tick for correct response and a cross for a wrong response followed by an overall grade. Both teachers indicated "good" for learners who performed well and no comment on learners who did not perform well. The scripts did not have any form of basic level comments for learners to reflect on their performance. Sadler (1989) adds that teachers must provide comments for the learners work rather than just marking their work as correct or wrong. It can be therefore suggested from the findings that the prime interest of the assessment was to provide a grade as a form of feedback which is far removed from supporting learning.

Similar findings were noted in a study by Susuwele-Banda (2005) who noted that teachers were interested in providing grades and simply crossing wrong responses. This study was far back in the 2000 before the integration of CA in the teaching and learning process. This is an indicator that the issue of effective feedback has not been entrenched into the education system despite the reform. It is therefore noted from participant's continuous assessment practices regarding the feedback provided to learners was not rich enough to support learning.

This finding raises serious questions about the feedback practice as it does not inform learning. According to Sadler (1989) such feedback does not meet formative assessment goal as it does not intend to fill the existing learning gap. Such teacher feedback practices leave learning to chance. The kind of feedback 
by participating teachers suggests that the primary interest was on ushering rewards or grades with the belief that learners would be prompted to improve.

In their literature, Fautly and Savage (2008) note that giving feedback to learners goes beyond telling them what is it they are doing wrong. They stress that feedback involves dialogue between the teacher and students. $\mathrm{Vu}$ and Dall'Alba (2007) noted that feedback must be accompanied by critical comments and possible suggestions for improvement. Greenstein (2010) adds that provision of feedback must focus on strengths as well as areas which require further improvement. Fautly and Savage (2008) point out that feedback involves dialogue between the teacher and the learner, as such the feedback must be detailed and comprehensive enough to stimulate student achievement in the future. This feedback is often known as feed forward as it has a bearing on learner's future performance (Fautly \& Savage, 2008). In addition, Onyefulu (2018), in her study recommended that teachers need to explain to students on how their scores were derived by meeting them as a group or individuals. The participating teachers could have done better if they were able to provide models illustrating the expected way of responding to continuous assessment tasks.

With regard to the use of learner feedback derived from formal assessment procedures, the majority of teachers indicated that they use the results for promotion purposes except for teacher BT3 and ST3. Other teachers BT2, ST1, ST2, LT1 and LT2 indicated that feedback received from learners is used for promotion purpose. The use of assessment results for promotion purposes counters the spirit behind the CA feedback practices which aim at improving the teaching and learning process.

BT3 uses learner feedback in order to strategise on how best to help the learners understand the content... so I first help them so that they can understand English and secondly they can be able to read and write in English... This is a typical example of a teacher adjusting the teaching as a result of the learner feedback. According to Yorke (2003) this feedback practice shows that the teacher used assessment feedback to adjust and improve their teaching.

While feedback mechanism aims at improving learning, the findings revealed that teachers were working under strenuous context due to high class sizes and high workload as highlighted by ST1, ST2 and LT1. The lesson observation showing teachers connecting lesson to lesson is an important indicator that stifled provision of effective feedback to learners during the teaching and learning process. The teacher's interest was therefore to cover content within a limited time. In addition, the large class sizes provides unrealistic environment for teachers to provide individual feedback to learners through the use of comments on the regular formal assessment tasks them are given.

\section{Conclusion and Implications}

The findings of the study reveal that teacher feedback aiming at facilitating the teaching and learning process is far from being attained. The forms of feedback 
still align with the old philosophies which lean on summative orientation. The substantial time that teachers are supposed to provide productive feedback is during the teaching and learning process. The spontaneous and incidental feedback given to learners during the informal assessment procedures in class such as question and answer has the ability to affect the learners in one way or the other. Spontaneous feedback such as ignoring learners' responses outright has the ability to demoralise learners.

It is therefore important that teachers must be careful and very conscious of the comments and the nonverbal cues they direct towards learners during the informal assessment activities in an ongoing lesson. They must make sure that their actions have as minimal side effects as possible. As for the formal assessment which is systematic, teachers are supposed to craft feedback in a way learners can reflect on their work thereby spurring further effort towards their learning. It is therefore important that schools must frequently organise in-service training to remind each other of the power of feedback in both formal and informal situations, thus building feedback literacy.

The MoEST must therefore create the context that would allow teachers to make effective feedback to learners by reducing class sizes. Feedback delivered to learners whether formal or written is the crux of learner improvement, it is therefore important for MoEST to enhance continuous professional development aiming at enhancing feedback literacy.

\section{Conflicts of Interest}

The authors declare no conflicts of interest regarding the publication of this paper.

\section{References}

Berhe, T., \& Embiza, S. (2015). Problems and Prospects of Implementing CA at Adigrat. Journal of Education and Practice, 6, 19-26.

Bill, B., \& Marie, C. (2014). Formative Assessment for Teaching and Learning. Sage Publication.

Black, P., \& William, D. (1998). Assessment and Classroom Learning. Assessment in Education, 5, 7-74. https://doi.org/10.1080/0969595980050102

Black, P., \& William, D. (1998). Inside the Black Box: Raising Standards through Classroom Assessment. Phi Delta Kappa, 80, 139-148.

Boud, D. (2000). Sustainable Assessment: Rethinking Assessment for the Learning Society. Studies in Continuing Education, 22, 151-167. https://doi.org/10.1080/713695728

Brookhart, S. M., \& Nitko, A. J. (2008). Assessment and Grading in Classrooms. Upper Saddle River, Pearson Prentince Hall.

Brown, G. T. L. (2004). Teacher's Instructional Conceptions: Assessments Relationship to Learning, Teaching, Curriculum and Teacher Efficacy. In Joint Conference of the Australian and New Zealand Associations for Research in Education (AARE/NZALE).

Chilora, H., du Plessis, J., Kamingira, Y., Mchazime, H., Miske, S., Phillips, A., \& Zembeni, G. (2003). Continuous Assessment for Standard 3: A Training Manual for Educators in Malawi. Malawi Institute of Education and Improving Educational Quality 
Project.

Chiziwa, W. K. M. C., \& Kunkwenzu, E. D. (2021). Investigating Teacher Assessment Practices in the Teaching of Social Studies in Malawian Primary Schools. Open Journal of Social Sciences, 9, 480-495.

Crooks, T. J. (1998). The Impact of Classroom Evaluation Practices on Students. Review of Educational Research, 34, 43-51.

DoE (2008). Plan and Conduct Assessment. Department of Education.

Falchikov, N. (2005). Improving Assessment through Student's Involvement: Practical Solutions for Aiding Learning in Higher and Further Education. Routledge.

Fautly, M., \& Savage, J. (2008). Assessment for Learning and Teaching in Secondary Schools. Learning Matters Ltd. https://doi.org/10.4135/9781446278642

Ferris, D. R. (2014). Responding to Student Writing: Teacher Philosophies and Practices. Assessing Writing, 19, 6-23. https://doi.org/10.1016/j.asw.2013.09.004

Gay, L. R., Mills, G. E., \& Airasian, P. (2006). Educational Research Competencies for Analysis and Applications. (8th ed.). Pearson Prentice Hall Publications.

Gorlewski, J. (2008). Research for the Classroom: Formative Assessment: Can You Handle the Truth? The English Journal, 98, 94-98.

Greenstein, L. (2010). What Teachers Really Need to Know about Formative Assessment? ASCD.

Hattie, J., \& Timperley, H. (2007). The Power of Feedback. Review of Educational Research, 77, 81-112. https://doi.org/10.3102/003465430298487

Jansen, J. D. (1998). Curriculum Reform in South Africa: A Critical Analysis of Outcomes-Based Education. Cambridge Journal of Education, 28, 321-331. https://doi.org/10.1080/0305764980280305

Kaambankadzanja, D. (2005a). Outcome Based Education (OBE) Curriculum-The Malawian Approach for Primary Curriculum \& Assessment Reform (PCAR). In, The Conceptualisation Conference for Initial Primary Teacher.

Kaambankadzanja, D. (2005b). The Primary Curriculum and Assessment Reform (PCAR): The Process, The Challenges and the Way forward. In National Education Conference.

Kothari, C. R. (2004). Research Methodology, Methods and Techniques. New Age International Publishers.

Macintosh, H. (2003). The Role of Assessment in OBE. In M. Coleman, M. Graham-Jolly, \& D. Middlewood (Eds.), Managing the Curriculum in South African Schools. Commonwealth Secretariat.

MacMillan, J. H. (2004). Educational Research Fundamentals for the Consumer (4th ed.). Pearson Education Inc.

Merriam, S. (2002). Qualitative Research and Case Study Applications in Education. Jossey-Bass

MOE, \& MIE (2007). Primary Curriculum and Assessment Reform, Journeys through PCAR (6) Standard 2 Teacher' Orientation Manual. MIE.

MoEST (2019). The 2018/19 Education Sector Performance Report, Strengthening Education Management and Accountability to Improve Learning Outcomes for All. MoEST.

MoEST, \& MIE (2006). PCAR, Standard 1 Teacher's Orientation Manual. MIE.

Natriello, G. (1987). The Impact of Evaluation Process on Students. Educational Psychologist, 22, 155-175. https://doi.org/10.1207/s15326985ep2202_4 
Nicol, D. J., \& Macfarlan-Dick, D. (2006). Formative Assessment and Self-Regulated Learning: A Model and Seven Principles of Good Feedback Practices. Studies in Higher Education, 31, 199-218. https://doi.org/10.1080/03075070600572090

Onyefulu, C. (2018). Assessment Practices of Teachers in Selected Primary and Secondary Schools in Jamaica. Open Access Library Journal, 5, e5038.

Ramaprasad, A. (1983). On Definition of Feedback. Behavioral Sciences, 28, 4-13. https://doi.org/10.1002/bs.3830280103

Rust, C. (2002). The Impact of Assessment on Student Learning: How Can Research Literature Help to Inform the Development of Departmental Assessment Strategies and Learner-Centred Assessment Strategies. Active Learning in Higher Education, 3, 145-158. https://doi.org/10.1177/1469787402003002004

Sadler, D. R. (1989). Formative Assessment and the Design of Instructional Systems. Instructional Science, 18, 119-144. https://doi.org/10.1007/BF00117714

Shute, V. (2008). Focus on Formative Feedback. Review of Educational Research, 78, 153-189. https://doi.org/10.3102/0034654307313795

Susuwele-Banda, W. J. (2005). Classroom Assessment in Malawi: Teachers Perceptions and Practices in Mathematics. Doctoral Thesis, Virginia Polytechnic Institute and State University.

Tuckman, B. (1994). Conducting Educational Research (8th ed.). Brace College Publishers.

Volante, K. L., \& Beckett, D. (2017). Formative Assessment and the Contemporary Classroom: Synergies and Tensions between Research and Practice. Canadian Journal of Education, 24, 39-255.

Vu, T. T., \& Dall'Alba, G. (2007). Students' Experience of Peer Assessment in a Professional Course. Assessment and Evaluation in Higher Education, 32, 541-556. https://doi.org/10.1080/02602930601116896

Walliman, N. (2011). Research Methods the Basics. Routledge. https://doi.org/10.4324/9780203836071

Yin, R. K. (2002). Case Study Research: Design and Methods. SAGE Publications.

Yorke, M. (2003) Formative Assessment in Higher Education: Moves towards Theory and Enhancement of Pedagogic Practice. Higher Education, 45, 477-501. https://doi.org/10.1023/A:1023967026413 